\title{
Green synthesis, characterization and catalytic activity of natural bentonite-supported copper nanoparticles for the solvent-free synthesis of 1-substituted $1 \mathrm{H}$-1,2,3,4-tetrazoles and reduction of 4-nitrophenol
}

\author{
Akbar Rostami-Vartooni $^{*} 1, \S$, Mohammad Alizadeh $^{1}$ and Mojtaba Bagherzadeh ${ }^{2}$
}

\section{Full Research Paper}

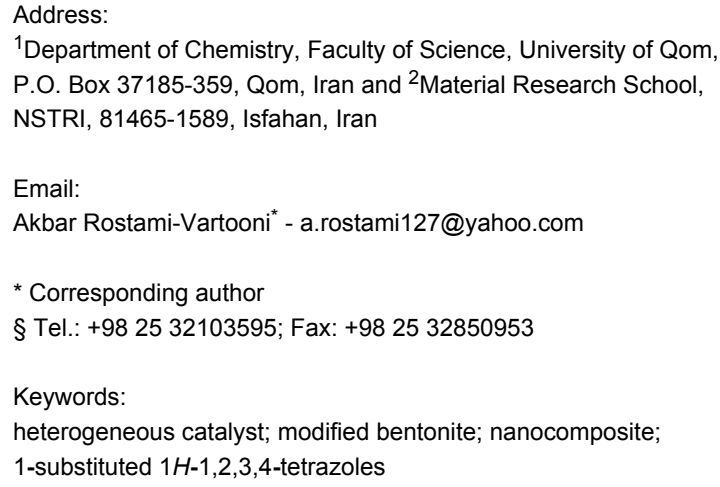

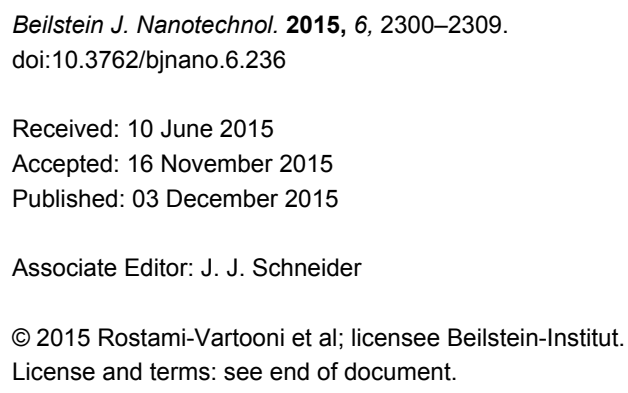

\begin{abstract}
In this study, $\mathrm{Cu}$ nanoparticles were immobilized on the surface of natural bentonite using Thymus vulgaris extract as a reducing and stabilizing agent. The natural bentonite-supported copper nanoparticles (Cu NPs/bentonite) were characterized by FTIR spectroscopy, X-ray diffraction (XRD), X-ray fluorescence (XRF), field emission scanning electron microscopy (FE-SEM), energy dispersive X-ray spectroscopy (EDS), transmission electron microscopy (TEM), selected area electron diffraction (SAED) and Brunauer-Emmett-Teller (BET) analysis. Afterward, the catalytic performance of the prepared catalyst was investigated for the solvent-free synthesis of 1-substituted $1 H$-1,2,3,4-tetrazoles and reduction of 4-nitrophenol (4-NP) in water. It was found that the $\mathrm{Cu} \mathrm{NPs} /$ bentonite is a highly active and recyclable catalyst for related reactions.
\end{abstract}

\section{Introduction}

The development of new methodologies for the preparation of heterogeneous catalysts is of great interest in organic synthesis [1]. Metal nanoparticles immobilized on supports such as carbon, zeolites, clay, metal oxides, graphene, etc., have been successfully applied as heterogeneous catalysts due to their interesting structures and properties [2-6]. The extremely small scale of nanoparticles (NPs) is the main factor leading to their surprising reactivity as compared to their corresponding bulk metals [7]. However, most of these supports suffer from inefficiency to achieve highly distributed and stable metal NPs.

In recent decades, the use of natural bentonites has been studied due to their high specific surface area, low cost, ordered structure, thermal stability, high safety, high exchange capacity and 
intercalation abilities [8]. Smectites are major clay minerals in bentonite with an aluminum octahedral sheet sandwiched between two silica tetrahedral sheets [9]. These layered materials are very promising supports for the design and preparation of green catalysts [10].

Tetrazoles are among the heterocycles most applied in medicine and industry due to their structural potential such as their usage as an isosteric substituent for carboxylic acids [11], analytical reagents and biological applications $[12,13]$. Therefore, nowadays attention and progress in synthesis of these heterocycles play an essential role in organic, medicinal and synthetic chemistry [14-16]. During recent research on tetrazoles, 1-substituted $1 H-1,2,3,4$-tetrazoles was found to be a special category due to their biological activity [16].

The plant biosynthesis of nanoparticles immobilized on natural supports is a subject of new research as little has been published on this topic $[17,18]$. Therefore, the use of plants as a natural and biological source for biosynthesis of nanoparticles should be explored.

Common thyme with the scientific name Thymus vulgaris is one of the plants indigenous to Iran which is valued for its antiseptic and antioxidant properties [19]. Thymol (1), carvacrol (2), $p$-cymene (3) and $\gamma$-terpinene (4) are the major components found in Thymus vulgaris (Scheme 1) [19].
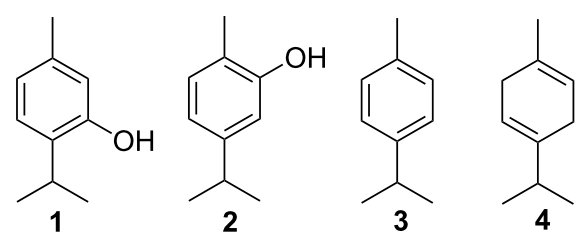

Scheme 1: The major components of Thymus vulgaris. Thymol (1), carvacrol (2), $p$-cymene (3) and $y$-terpinene (4).

As a continuation of our research on heterogeneous catalysts $[20,21]$, we report a new protocol for the preparation of $\mathrm{Cu}$ NPs/bentonite by Thymus vulgaris extract and catalytic applications as a novel heterogeneous catalyst for the synthesis of 1-substituted $1 H$-1,2,3,4-tetrazoles and reduction of 4-nitrophenol (4-NP). It was found that $\mathrm{Cu}$ NPs/bentonite is a highly active and recyclable catalyst for related reactions. The obtained results will be presented and described here.

\section{Experimental \\ Instruments and reagents}

All reagents were purchased from the Merck and Sigma-Aldrich and used without further purification. The bentonite and
Thymus vulgaris plant used in this paper were collected from the Vartoon region (Isfahan, Iran). The IR spectra were recorded on a JASCO, FT/IR-6300 instrument in $\mathrm{KBr}$ pellets. The NMR spectra were obtained on a Brucker Avance $90 \mathrm{MHz}$ spectrometer, using tetramethylsilane (TMS) as an internal standard. The melting points were taken in open capillary tubes with a Büchi 510 melting point apparatus and were uncorrected. Thin-layer chromatography (TLC) was performed on silica gel polygram SIL G/UV 254 plates. XRD analysis was performed on a Philips powder diffractometer type PW 1373 goniometer, which was equipped with a graphite monochromator crystal. The XRF analysis of the catalyst was performed with a Bruker S4 instrument. The morphology and particle dispersion was investigated by FE-SEM (Cam scan MV2300). The chemical composition of the modified bentonite was measured by EDX performed in a SEM. TEM images were obtained using a Philips-EM-2085 transmission electron microscope with an accelerating voltage of $100 \mathrm{kV}$. Nitrogen adsorption isotherms were performed on a volumetric gas adsorption apparatus (BEL Japan, Belsorp-max). The pore distributions and pore volumes were calculated using the adsorption branch of the $\mathrm{N}_{2}$ isotherms based on the Barrett-Joyner-Halenda (BJH) model. The specific surface area was calculated from the BET equation.

\section{Preparation of Thymus vulgaris extract}

$5 \mathrm{~g}$ of a dried powder of Thymus vulgaris leaves and pedicles was extracted by boiling in $30 \mathrm{~mL}$ double distilled water for $15 \mathrm{~min}$ and the aqueous extract was centrifuged at $7000 \mathrm{rpm}$ to obtain the supernatant as an extract. This solution of the extract was used for the synthesis of $\mathrm{Cu}$ NPs/bentonite.

\section{Preparation of $\mathrm{Cu}$ NPs/bentonite}

For green synthesis of $\mathrm{Cu}$ NPs/bentonite composite, $10 \mathrm{~g}$ natural bentonite was dispersed in $100 \mathrm{~mL}$ of $0.2 \mathrm{M}$ $\mathrm{CuSO}_{4} \cdot 5 \mathrm{H}_{2} \mathrm{O}$ under continuous stirring. After separation of quartz and feldspar precipitated in container, the above extract was added. This dispersion was stirred at $80{ }^{\circ} \mathrm{C}$ for $4 \mathrm{~h}$. The prepared $\mathrm{Cu}$ NPs/bentonite was separated by filtration, washed several times with deionized water and absolute ethanol and dried at $100{ }^{\circ} \mathrm{C}$ for $2 \mathrm{~h}$.

\section{General experimental procedure for the synthesis of 1-substituted \\ $1 H$-1,2,3,4-tetrazoles}

A mixture of amine $(2 \mathrm{mmol}), \mathrm{NaN}_{3}(2 \mathrm{mmol})$, triethyl orthoformate $(2.4 \mathrm{mmol})$ and $\mathrm{Cu} \mathrm{NPs} /$ bentonite $(0.05 \mathrm{~g})$ was heated up to $120^{\circ} \mathrm{C}$ for $3 \mathrm{~h}$ and stirred. After completion of the reaction (monitored by TLC), the reaction mixture was cooled to room temperature and diluted with cold water $(5 \mathrm{~mL})$ and extracted with ethyl acetate $(3 \times 10 \mathrm{~mL})$. The catalyst was filtered and washed with water and ethanol. The combined 
organic layers were washed with brine and dried over the anhydrous $\mathrm{MgSO}_{4}$ and concentrated and crystallized with EtOAchexane to give different tetrazoles. All compounds were known and were characterized by spectral analysis or melting points [14].

\section{Catalytic reduction of 4-NP}

Typically, $25 \mathrm{~mL}$ of $4-\mathrm{NP}$ aqueous solution $(2.5 \mathrm{mM})$ was mixed with $15 \mathrm{mg}$ of the $\mathrm{Cu}$ NPs/bentonite in a beaker, stirring constantly for $2 \mathrm{~min}$. Next, $25 \mathrm{~mL}$ of freshly prepared aqueous $\mathrm{NaBH}_{4}(0.25 \mathrm{M})$ was added and the mixture was allowed to stir at room temperature until the deep yellow solution became colorless. $1.0 \mathrm{~mL}$ of the solution was extracted and diluted to $25 \mathrm{~mL}$ for further UV-vis absorption analysis at certain intervals. The concentration of 4-NP was determined spectrophotometrically at a wavelength of $400 \mathrm{~nm}$.

\section{Results and Discussion Preparation and characterization of Cu NPs/ bentonite}

The $\mathrm{Cu}$ NPs/bentonite composite was prepared by a simple and inexpensive method involving the immobilization of $\mathrm{Cu}$ NPs on bentonite using an aqueous extract of Thymus vulgaris without the usage of any special capping agents or surfactant template. The plant not only functioned as a reductant, but also served as a stabilizer for the formation of $\mathrm{Cu}$ NPs on the surface of natural bentonite. The obtained $\mathrm{Cu}$ NPs/bentonite was fully characterized by XRF, FTIR, XRD, FE-SEM, EDX, TEM, SAED and BET analyses.

As depicted in Figure 1, the UV-vis spectra of the plant showed $\pi \rightarrow \pi^{*}$ transitions of aromatics in the extract. Also, given the presence of monoterpenes such as thymol and carvacrol, these transitions are probably related to the mentioned compounds involved in the reduction process and formation of copper nanoparticles deposited on bentonite surface through $\pi$-electron interactions [17,21]. Hence, the extract of Thymus vulgaris acts as the reductant as well as the stabilizer.

The XRF results in Table 1 show the variations in the chemical composition of bentonite upon successful modification with $\mathrm{Cu}$ (4.3 wt \%). The presence of $\mathrm{Cu}$ and the absence of $\mathrm{Na}_{2} \mathrm{O}$ in these results as compared with the XRF results of natural bentonite [22] were due to ion exchange of $\mathrm{Na}^{+}$ions from the bentonite with $\mathrm{Cu}^{2+}$ ions, followed by reduction under Thymus vulgaris extract. On the other hand, the reduction and ion exchange processes are simultaneous.

\begin{tabular}{ll}
$\begin{array}{l}\text { Table 1: Typical approximate compositional analysis of } \mathrm{Cu} \mathrm{NPs/} \\
\text { bentonite. }\end{array}$ \\
Constituent & Typical (\%) \\
\hline $\mathrm{SiO}_{2}$ & 62.71 \\
$\mathrm{Al}_{2} \mathrm{O}_{3}$ & 12.3 \\
$\mathrm{~K}_{2} \mathrm{O}$ & 0.47 \\
$\mathrm{CaO}$ & 2.06 \\
$\mathrm{MgO}$ & 1.35 \\
$\mathrm{Fe}_{2} \mathrm{O}$ & 1.06 \\
$\mathrm{TiO}_{2}$ & 0.07 \\
$\mathrm{Cu}^{\mathrm{LO}}$ & 4.27 \\
\hline
\end{tabular}

aLOI: loss on ignition $\left(1000^{\circ} \mathrm{C}, 2 \mathrm{~h}\right)$.

FTIR spectra of the natural (a) and modified (b) bentonite are presented in Figure 2. As can be seen in Figure 2, four typical groups of IR bands can be clearly distinguished in both spectra. These have been previously reported and assigned to the following major vibrations: below $400 \mathrm{~cm}^{-1}$, lattice vibrations occur, while pseudo-lattice vibrations are observed at about $500-700 \mathrm{~cm}^{-1}$; internal vibrations of $\mathrm{Si}-\mathrm{O}(\mathrm{Si})$ and $\mathrm{Si}-\mathrm{O}(\mathrm{Al})$ in tetrahedral or alumino- and silico-oxygen bridges emerge in the

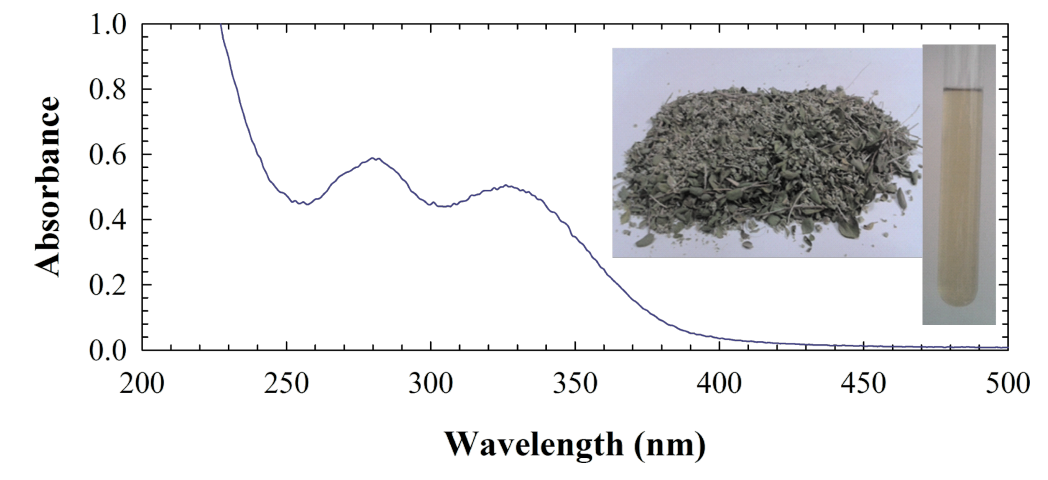

Figure 1: UV-vis spectrum of an aqueous extract of Thymus vulgaris. 


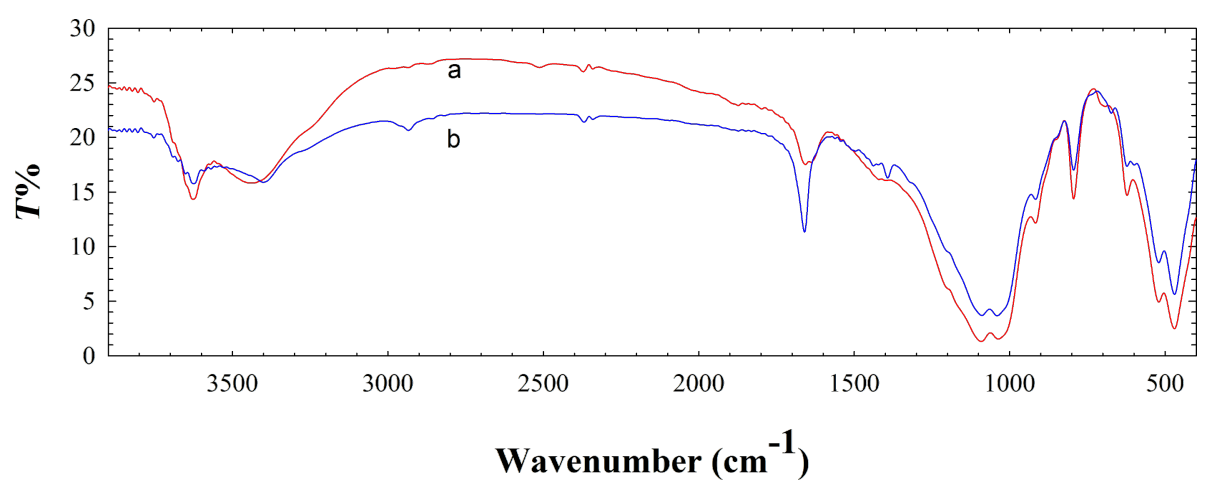

Figure 2: FTIR spectra of (a) natural bentonite and the (b) Cu NPs/bentonite composite.

range between 400 and $1200 \mathrm{~cm}^{-1}$, whereas the bands of adsorbed water and surface hydroxyls are evident at about $1630-1650 \mathrm{~cm}^{-1}$ and $3000-3800 \mathrm{~cm}^{-1}$, respectively [23-27]. The structural modifications of the tetrahedral and octahedral sheets due to the adsorbed $\mathrm{Cu}(\mathrm{II})$ cations and formation of $\mathrm{Cu}$ NPs on bentonite influenced the fundamental vibrations of the $\mathrm{Si}-\mathrm{O}$ and $\mathrm{H}_{2} \mathrm{O}$ groups (Figure $2 \mathrm{~b}$ ). From the FTIR spectrum of the modified bentonite sample (Figure $2 b$ ), it is notable that the broad band of water near $3430 \mathrm{~cm}^{-1}$ has shifted to higher frequencies in comparison to the natural bentonite (Figure 2a). Also, a new peak at $1385 \mathrm{~cm}^{-1}$ is observed for modified bentonite, the origin of which was interpreted in terms of substitution of the naturally present alkaline metals with $\mathrm{Cu}(\mathrm{II})$ ions as a result of the modification [28]. The observed results confirmed that the structural changes were acquired during the modification of bentonite. Further proof was obtained by the XRD and EDS results.

The XRD patterns of the raw bentonite (Figure 3a) and modified bentonite (Figure 3b) are shown in Figure 3. The XRD pattern in Figure 3a reveals that the principal constituents of the employed natural clay are montmorillonite (M) and quartz (Q), where the characteristic peaks located at $2 \theta=19.84,34.80$, and $61.84^{\circ}$ were indexed to $(020),(130)$, and (060) planes of montmorillonite, respectively, and $2 \theta=26.81,36.25$, and $48.84^{\circ}$ were indexed to (101), (110), and (201) planes of quartz, res-
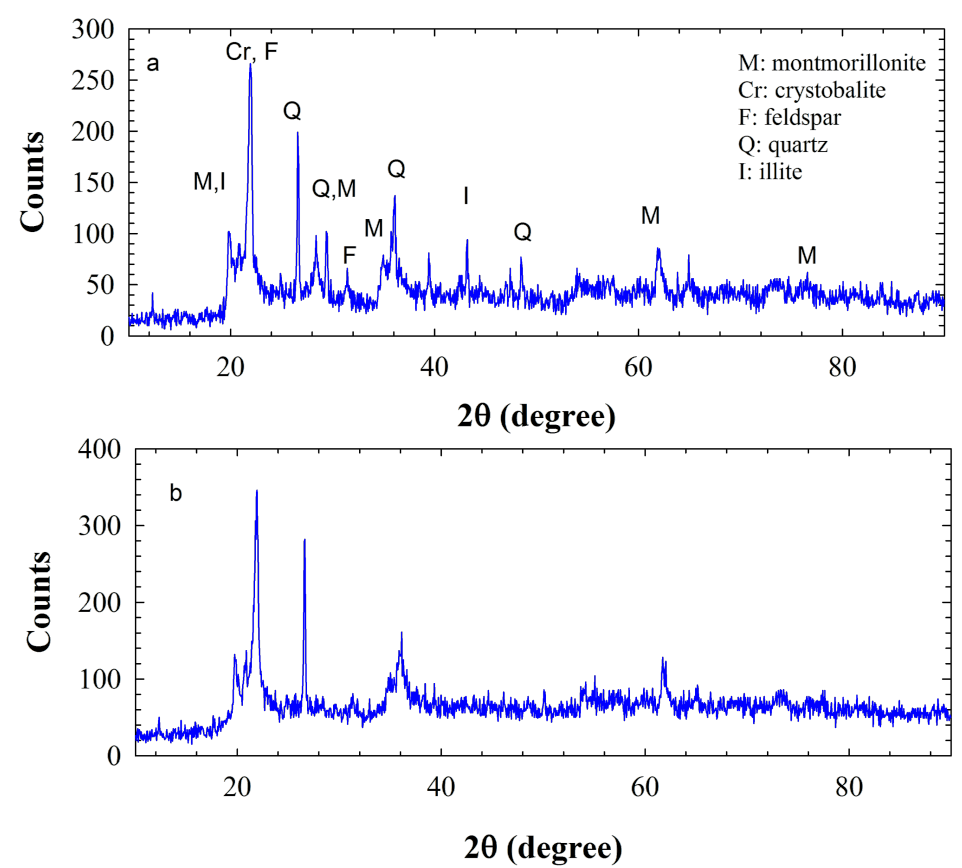

Figure 3: The XRD patterns of natural bentonite (a) and Cu NPs/bentonite (b). 
pectively. The other peaks are impurities corresponding to crystobalite, feldspar and illite [25]. It is expected that after modification of bentonite with $\mathrm{Cu}$, a number of new peaks appear at $2 \theta=40-55^{\circ}$ [29]. However, as can be seen in the XRD pattern of Figure $3 b$, no specific peaks were obtained for the $\mathrm{Cu}$ NPs. This might be due to the low percentage or high dispersion of $\mathrm{Cu}$ NPs in the bentonite matrix. However, the existence of $\mathrm{Cu}$ NPs can be confirmed by the EDS technique.

Figure 4 shows the FE-SEM of $\mathrm{Cu}$ NPs/bentonite. The sheetlike structure of montmorillonite can be seen in SEM images. These images show that the adsorption of $\mathrm{Cu}$ NPs can occur on both the external surface and interlayer spaces. However, in the EDS spectrum (Figure 5), peaks related to $\mathrm{Cu}(6.07 \% \mathrm{w} / \mathrm{w}), \mathrm{Si}$, $\mathrm{Al}, \mathrm{Mg}$ and $\mathrm{O}$ were observed.
The size of the as-prepared $\mathrm{Cu}$ NPs/bentonite was further examined by TEM. The histogram of the particle size distribution of $\mathrm{Cu}$ nanoparticles on the surface of bentonite is given in Figure $6 \mathrm{a}-\mathrm{c}$. The average size of the $\mathrm{Cu}$ NPs on bentonite was $56 \mathrm{~nm}$. The particles exhibited spherical morphology with a low tendency for agglomeration. Figure 6d (SAED) shows the measured selected area electron diffraction pattern of as-prepared $\mathrm{Cu}$ NPs/bentonite. This result indicates that the nanoparticles are crystalline and mainly composed of fcc $\mathrm{Cu}$. The SAED patterns of the $\mathrm{Cu}$ NPs/bentonite sample are used to characterize the planes, interplanar spacing, nanostructure and zone axis. These results verified the successful synthesis of $\mathrm{Cu}$ NPs on bentonite. In the presence of the Thymus vulgaris extract as a reducing and stabilizing agent, the $\mathrm{Cu}^{2+}$ ions convert to $\mathrm{Cu}$ NPs and immobilize on the surface of bentonite $[6,20,30-33]$.
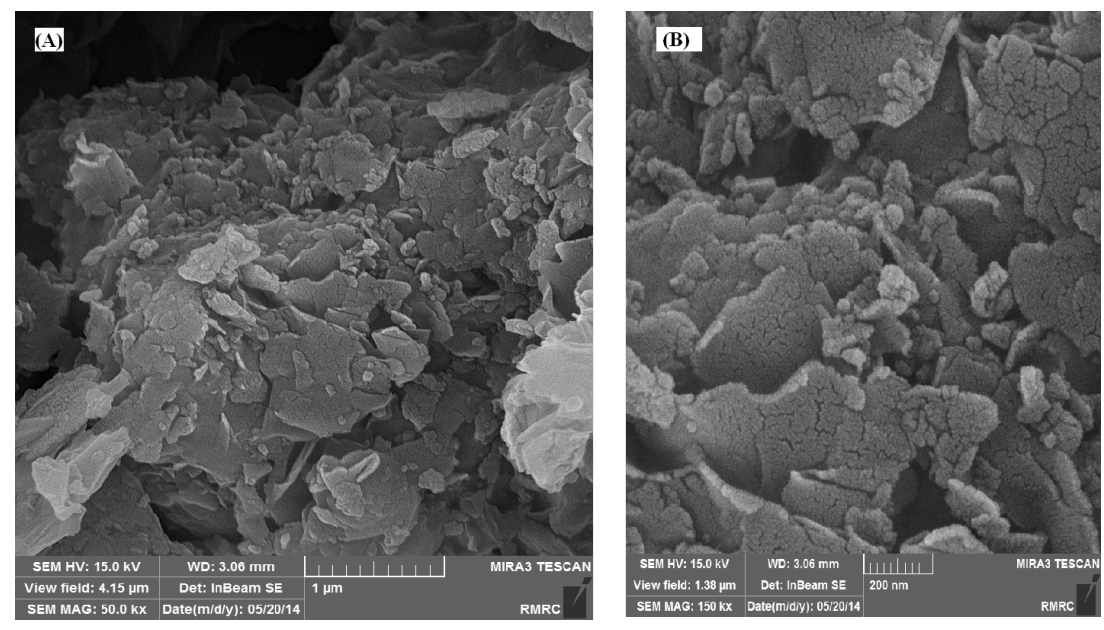

Figure 4: Typical FE-SEM images of Cu NPs/bentonite. Scale bar: (a) $1 \mu \mathrm{m}$ and (b) $200 \mathrm{~nm}$.

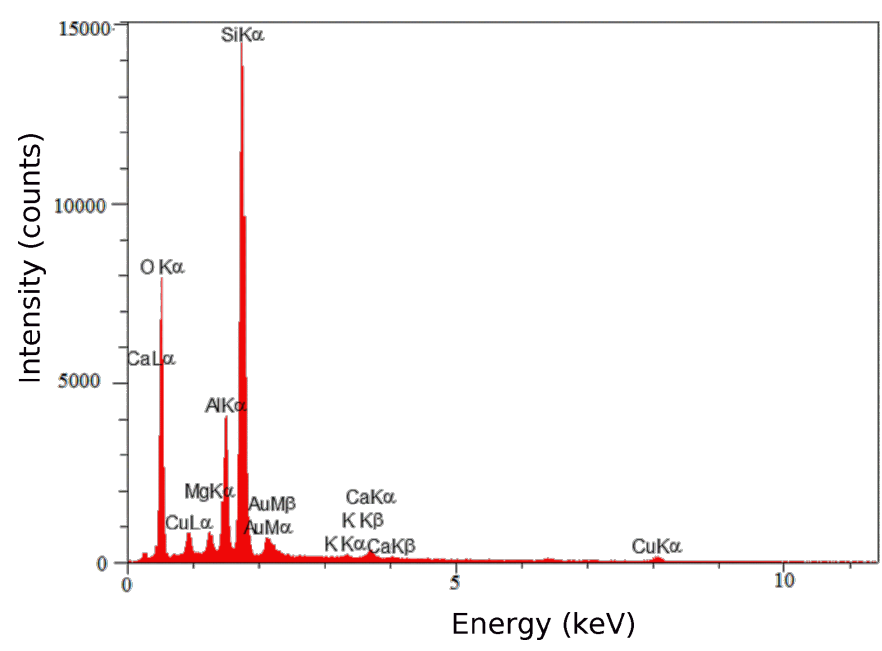

Figure 5: EDS spectrum of Cu NPs/bentonite. 

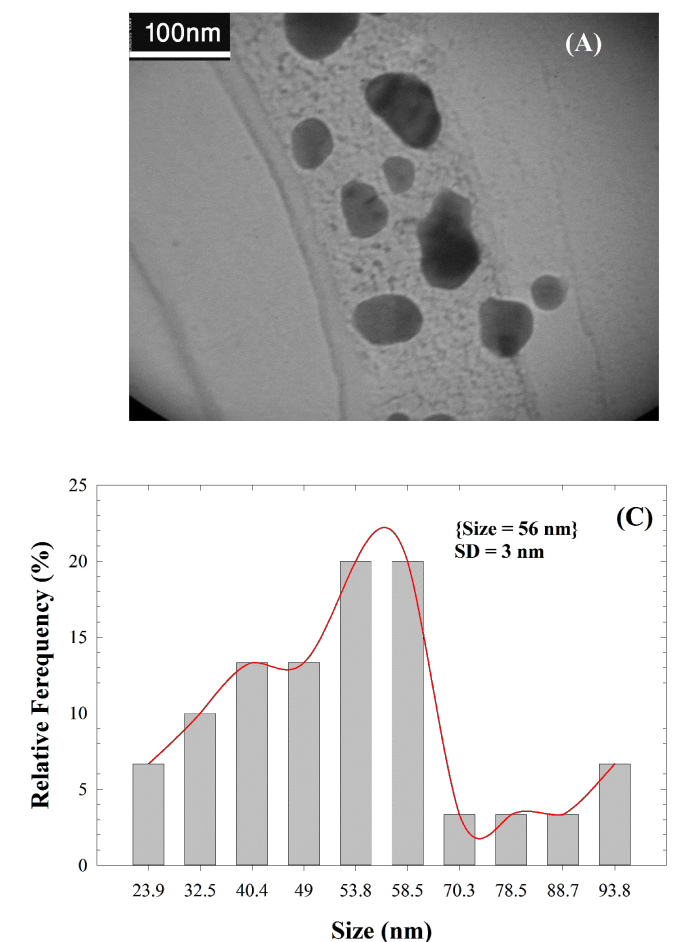
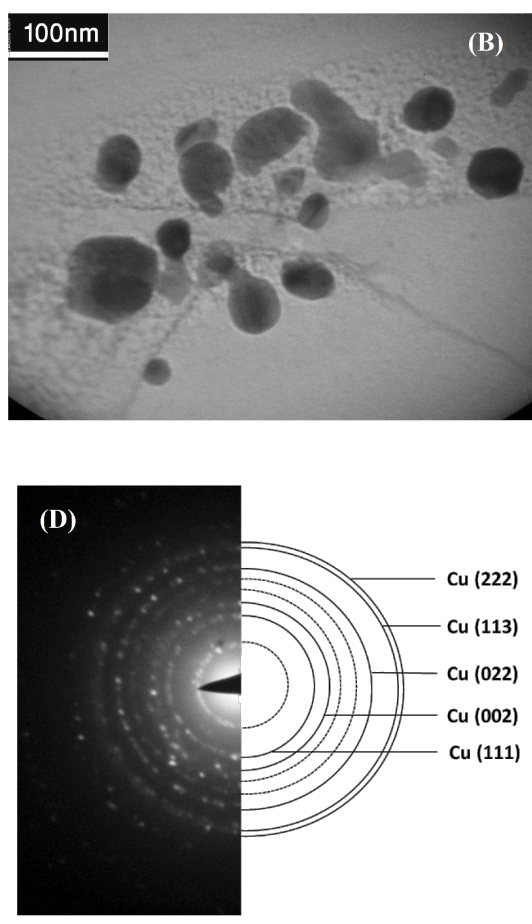

Figure 6: Typical TEM images of Cu NPs/bentonite $(a, b)$, the histogram of the particle size distribution of Cu nanoparticles on the bentonite surface (c) and corresponding SAED pattern (d).

The surface area measurements were performed on $\mathrm{Cu}$ NPs/ bentonite. Figure 7 shows the $\mathrm{N}_{2}$ adsorption-desorption isotherm and $\mathrm{BJH}$ pore size distribution plot of $\mathrm{Cu}$ NPs/ bentonite. The results indicate that the surface area, total pore volume and average pore diameter were $19.1 \mathrm{~m}^{2} / \mathrm{g}, 0.071 \mathrm{~cm}^{3} / \mathrm{g}$ and $14.79 \mathrm{~nm}$, respectively. For similar Iranian bentonite [34], the surface area, total pore volume and average pore diameter were $31.8 \mathrm{~m}^{2} / \mathrm{g}, 0.093 \mathrm{~cm}^{3} / \mathrm{g}$ and $11.7 \mathrm{~nm}$, respectively. The surface area and total pore volume of $\mathrm{Cu}$ NPs/bentonite decreased compared to the natural bentonite, whereas its pore size increased.

\section{Activity of Cu NPs/bentonite for the syn- thesis of 1-substituted $1 H$-1,2,3,4-tetrazoles}

For the further understanding of the role of $\mathrm{Cu}$ NPs/bentonite, a comprehensive study of the synthesis of 1-substituted $1 H$-1,2,3,4-tetrazoles was carried out (Scheme 2).

$$
\mathrm{RNH}_{2}+\mathrm{CH}(\mathrm{OEt})_{3}+\mathrm{NaN}_{3} \frac{\mathrm{Cu} \mathrm{NPs} / \text { bentonite }}{\text { solvent-free, } 120^{\circ} \mathrm{C}, 3 \mathrm{~h}} \mathrm{R}-\stackrel{\mathrm{N}}{\stackrel{\mathrm{N}}{\mathrm{N}}=\mathrm{N}}
$$

Scheme 2: Synthesis of 1-phenyl-1H-1,2,3,4-tetrazole ( $\mathrm{R}=$ phenyl).
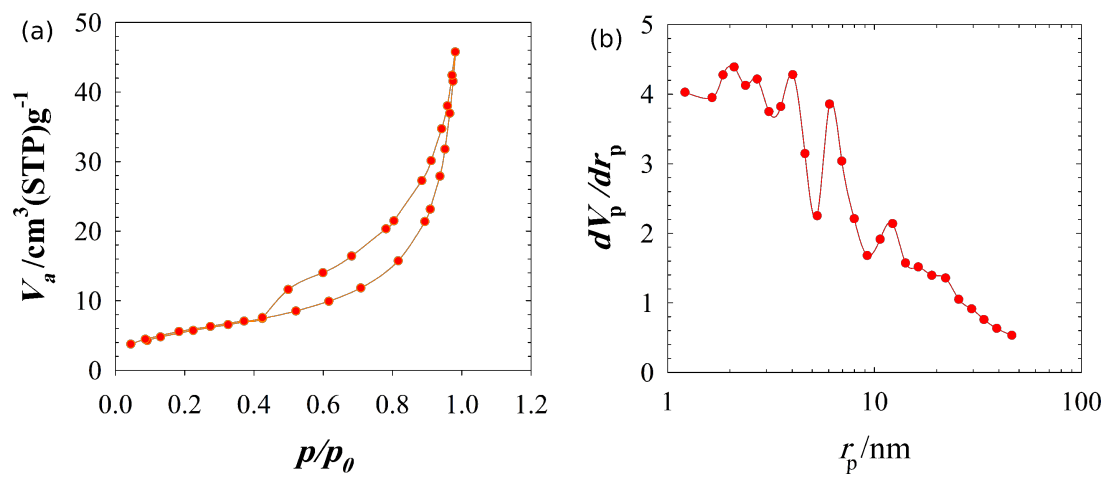

Figure 7: The $\mathrm{N}_{2}$ adsorption-desorption isotherm (a) and Barrett-Joyner-Halenda (BJH) pore size distribution plot of Cu NPs/bentonite (b). 
Initial studies were performed in order to optimize the reaction conditions for the synthesis of 1-phenyl-1H-1,2,3,4-tetrazole. As proved by control experiments, no reaction occurs in the absence of $\mathrm{Cu}$ NPs/bentonite. The best result was obtained with the with 2.0:2.0:2.4 molar ratio of aniline/sodium azide/triethyl orthoformate, in the presence of $\mathrm{Cu} \mathrm{NPs} /$ bentonite $(0.05 \mathrm{~g})$ under solvent-free conditions at $120{ }^{\circ} \mathrm{C}$.

A series of primary aromatic amines were converted into the corresponding 1 -substituted tetrazoles with sodium azide and triethyl orthoformate using $\mathrm{Cu}$ NPs/bentonite in high yields under thermal and solvent-free conditions (Table 2). The influence of various substituents in different ortho, meta or para positions on the type of products were examined. Amines containing both electron-releasing and electron-withdrawing groups underwent the conversion in good to excellent yield.

The $\mathrm{Cu}$ NPs/bentonite likely plays an important role in the preparation of 1-substituted $1 H$-1,2,3,4-tetrazole as a Lewis acid and the plausible mechanism is shown in Scheme 3 [14]. The

Table 2: Preparation of 1 -substituted $1 H-1,2,3,4$-tetrazoles in the presence of $\mathrm{Cu}$ NPs/bentonite by reaction between sodium azide, primary amines and triethyl orthoformate at $120^{\circ} \mathrm{C}^{\mathrm{a}}$

\begin{tabular}{|c|c|c|c|}
\hline Entry & Substrate & Product & Yield [\%] ${ }^{\mathrm{b}}$ \\
\hline 1 & & & 93 \\
\hline 2 & & & 85 \\
\hline 3 & & & 94 \\
\hline 4 & & & 87 \\
\hline 5 & & & 83 \\
\hline 6 & & & 85 \\
\hline 7 & & & 87 \\
\hline 8 & & & 87 \\
\hline 9 & & & 88 \\
\hline 10 & & & 92 \\
\hline 11 & & & 86 \\
\hline 12 & & & 83 \\
\hline
\end{tabular}

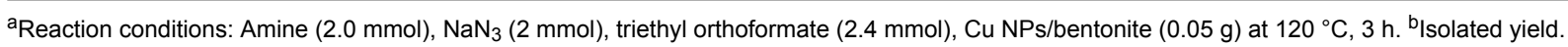



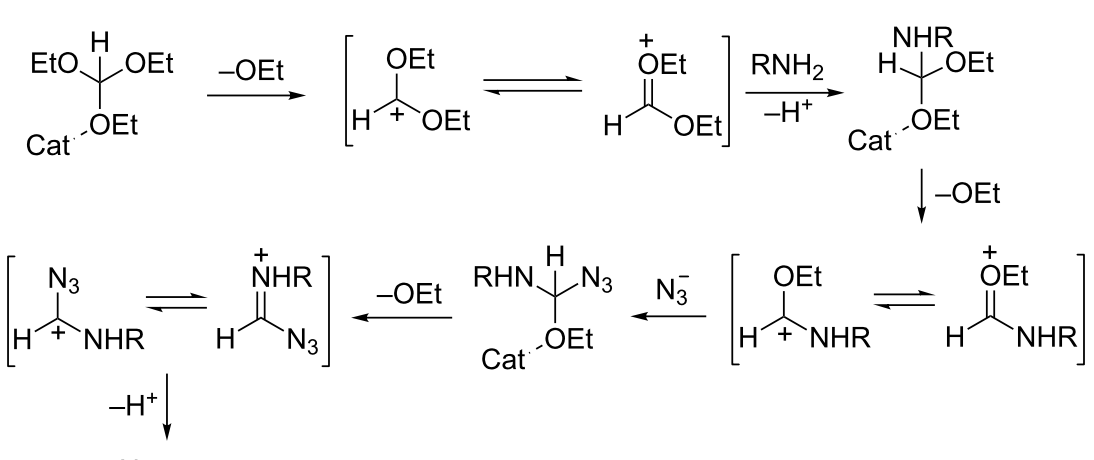

${ }_{\mathrm{H}}^{\mathrm{N}_{3}}=\underset{\mathrm{R}}{\stackrel{\text { Heat }}{\longrightarrow}} \stackrel{\substack{\mathrm{N}=\mathrm{N} \\ \mathrm{N}}}{\mathrm{N}-\mathrm{R}} \quad$ Cat = Cu NPs/bentonite

Scheme 3: The proposed mechanism for the preparation of 1-phenyl-1H-1,2,3,4-tetrazole.

breakdown of the $\mathrm{C}-\mathrm{OEt}$ bond in triethyl orthoformate facilitates the elimination of $\mathrm{EtOH}$ and the final 1-substituted $1 H$-1,2,3,4-tetrazole is produced. The energy of these cleavages and formation of products are provided by the heat (Scheme 3 ).

The recyclability of $\mathrm{Cu} \mathrm{NPs} /$ bentonite in the preparation of 1-phenyl-1H-1,2,3,4-tetrazole was also investigated. As shown in Figure 8, no significant decrease in catalytic activity was observed for the recovered catalyst after four catalytic cycles. As compared with other literature works on the synthesis of 1-substituted $1 H$-1,2,3,4-tetrazole [35], the present work is comparable because it was carried out without solvent, at low reaction time, in the presence of a catalyst prepared from bentonite as an inexpensive and natural compound.

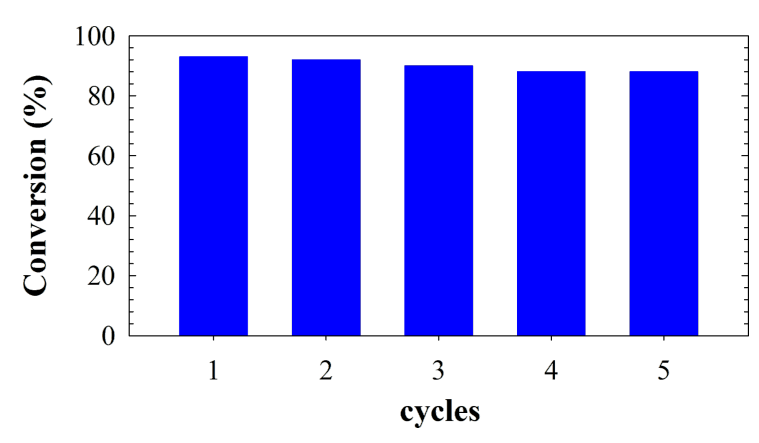

Figure 8: Conversion against number of catalytic cycles for the preparation 1-phenyl-1 $\mathrm{H}$-1,2,3,4-tetrazole with Cu NPs/bentonite for five successive cycles. Conditions: aniline $(2 \mathrm{mmol}), \mathrm{NaN}_{3}(2 \mathrm{mmol})$, triethyl orthoformate $(2.4 \mathrm{mmol})$, catalyst $(0.05 \mathrm{~g})$ at $120^{\circ} \mathrm{C}, 3 \mathrm{~h}$.

\section{Application of the Cu NPs/bentonite for the catalytic reduction of 4-NP}

Another reaction chosen as a model reaction to evaluate the catalytic activity of the $\mathrm{Cu}$ NPs/bentonite was the catalytic reduction of 4-NP to 4-aminophenol in the presence of $\mathrm{NaBH}_{4}$.
The concentration of 4-NP was monitored at given intervals by using UV-vis spectroscopy and the results are shown in Figure 9. The original absorption peak of 4-NP is centered at about $320 \mathrm{~nm}$ and shifts to $400 \mathrm{~nm}$ after addition of the $\mathrm{NaBH}_{4}$ solution. This is due to the formation of $p$-nitrophenolate ions under alkaline conditions with $\mathrm{NaBH}_{4}$ [36]. The absorption peak at $400 \mathrm{~nm}$ fully disappeared in the presence of $15 \mathrm{mg}$ of catalyst after a $90 \mathrm{~s}$ induction period. In similar conditions, the study was carried out at lower concentrations of $\mathrm{NaBH}_{4}$. The reaction time was 420 and $515 \mathrm{~s}$ in the presence of $2.5 \times 10^{-2}$ and $1.3 \times 10^{-2} \mathrm{M} \mathrm{NaBH}_{4}$, respectively. In addition, a reference experiment of $\mathrm{Cu} \mathrm{NPs} /$ bentonite with only 4-NP was carried out. After $12 \mathrm{~h}$, the 4-NP could not be reduced to 4-AP by the catalyst in the absence of $\mathrm{NaBH}_{4}$. The catalyst could be recovered and reused several times without significant loss of catalytic activity. In the presence of natural bentonite $(15 \mathrm{mg})$, no significant color change was observed in a similar reduction process within $3 \mathrm{~h}$. The catalytic reduction process using $\mathrm{Cu}$ NPs/bentonite can be summarized as follows: diffusion and adsorption of both $\mathrm{BH}_{4}{ }^{-}$, as a strong nucleophile, and 4-NP onto the $\mathrm{Cu}$ surface; followed by electron transfer from the $\mathrm{BH}_{4}{ }^{-}$to 4-NP; and finally, desorption of the generated 4 -aminophenol from the surface of the catalyst [37,38].

Since catalysis takes place on the $\mathrm{Cu}$ surface, $\mathrm{Cu}$ NPs/bentonite are much more reactive than the unmodified natural bentonite. Furthermore, it is found that the reduction of 4-NP over catalyst in the presence of a large excess of $\mathrm{NaBH}_{4}$ compared to 4-NP can be treated by a pseudo-first-order equation [18]: $\ln \left(C_{\mathrm{t}} / C_{0}\right)=\ln \left(A_{\mathrm{t}} / A_{0}\right)=-k t$, where $C_{\mathrm{t}}$ is the concentration of 4-NP at a reaction time $t, C_{0}$ is the initial concentration of 4-NP, $A_{\mathrm{t}}$ is the absorbance at any time $t$, and $A_{0}$ is the absorbance at time $t=0$. From the linear relations of $\ln \left(A_{\mathrm{t}} / A_{0}\right)$, shown in Figure 10, we found that the rate constant $(k)$ for this reaction is $0.041 \mathrm{~s}^{-1}$, which is comparable to that previously reported [39- 


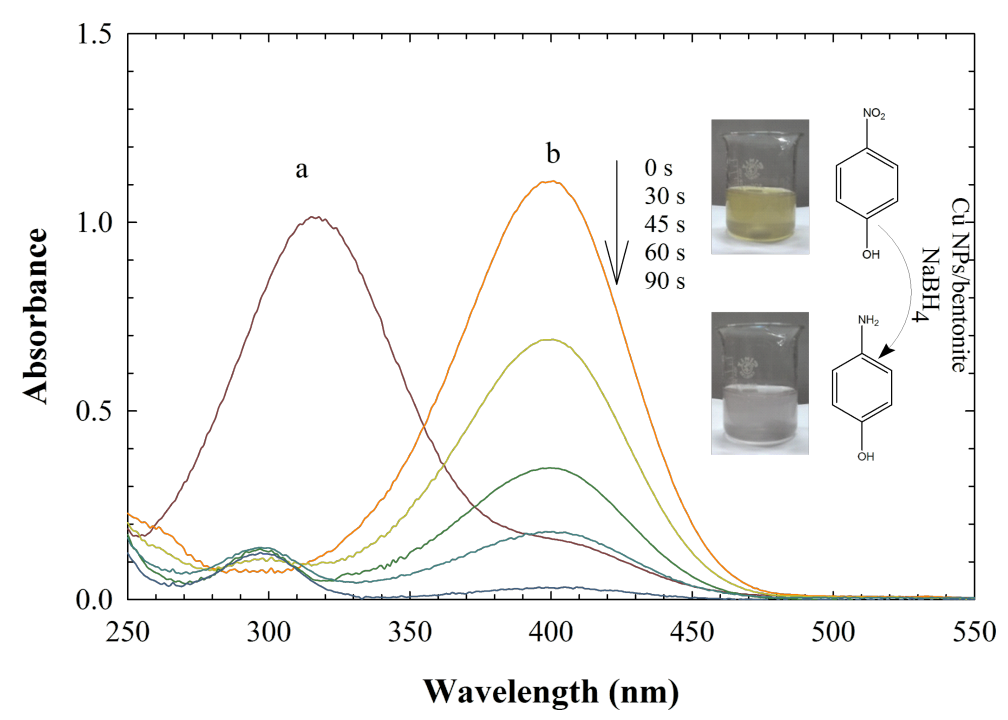

Figure 9: UV-vis absorption spectra of 4-NP (a) and 4-NP $+\mathrm{NaBH}_{4}$ (b) at several intervals. Conditions: $[4-\mathrm{NP}]=2.5 \times 10^{-3} \mathrm{M} ;[\mathrm{NaBH} 4]=0.25 \mathrm{M}$; catalyst $=15 \mathrm{mg}$.

42]. The enhanced reactivity of the $\mathrm{Cu}$ NPs/bentonite is related to the dispersion of $\mathrm{Cu}$ NPs particles in the support, which provides more accessible reactive sites for reduction of 4-NP.

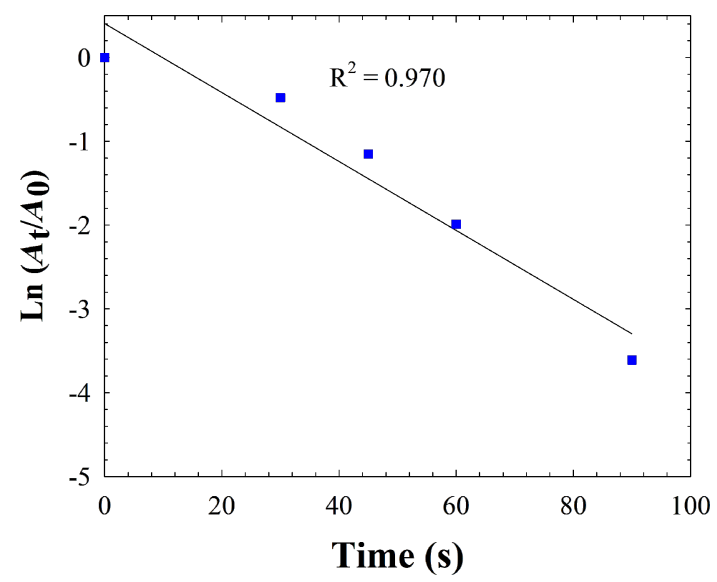

Figure 10: Plot of $\ln \left(A_{t} / A_{0}\right)$ vs irradiation time for 4-NP reduction. Conditions: $[4-\mathrm{NP}]=2.5 \times 10^{-3} \mathrm{M} ;\left[\mathrm{NaBH}_{4}\right]=0.25 \mathrm{M}$; catalyst $=15 \mathrm{mg}$.

\section{Conclusion}

In this study, copper nanoparticles supported on natural bentonite using a Thymus vulgaris extract as a reducing and stabilizing agent were prepared and characterized. This catalyst was found to be an efficient and recyclable heterogeneous catalyst for the synthesis of 1-substituted $1 H$-1,2,3,4-tetrazoles and reduction of 4-NP under mild conditions. The $\mathrm{Cu}$ NPs/ bentonite composite remained stable under several reactions.

\section{Acknowledgments}

We gratefully acknowledge the Iranian Nano Council and the University of Qom for the support of this work.

\section{References}

1. Mohammadi, B.; Hosseini Jamkarani, S. M.; Kamali, T. A.; Nasrollahzadeh, M.; Mohajeri, A. Turk. J. Chem. 2010, 34, 613-619. doi:10.3906/kim-0906-28

2. Roisson, P.; Brunelle, J. P.; Nortier, P. Catalyst Supports and Supported Catalysts, Technology and Applied Concepts; Butterworth: Boston, MA, U.S.A., 1987.

3. Tang, D.; Zhang, L.; Zhang, Y.; Qiao, Z.-A.; Liu, Y.; Huo, Q. J. Colloid Interface Sci. 2012, 369, 338-343. doi:10.1016/j.jcis.2011.12.014

4. Hirai, T.; Bando, Y. J. Colloid Interface Sci. 2005, 288, 513-516. doi:10.1016/j.jcis.2005.03.038

5. Kuang, Y.; Du, J.; Zhou, R.; Chen, Z.; Megharaj, M.; Naidu, R. J. Colloid Interface Sci. 2015, 447, 85-91. doi:10.1016/j.jcis.2015.01.080

6. Nasrollahzadeh, M.; Maham, M.; Rostami-Vartooni, A.; Bagherzadeh, M.; Sajadi, S. M. RSC Adv. 2015, 5, 64769-64780. doi:10.1039/C5RA10037B

7. Fakhri, P.; Nasrollahzadeh, M.; Jaleh, B. RSC Adv. 2014, 4, 48691-48697. doi:10.1039/C4RA06562J

8. Tang, X.-I.; Meng, X.; Shi, L. Ind. Eng. Chem. Res. 2011, 50, 7527-7533. doi:10.1021/ie200475x

9. Yi, D.; Huang, H.; Meng, X.; Shi, L. Ind. Eng. Chem. Res. 2013, 52, 6112-6611. doi:10.1021/ie400227r

10. Ghiaci, M.; Mostajeran, M.; Gil, A. Ind. Eng. Chem. Res. 2012, 51, 15821-15831. doi:10.1021/ie3021939

11. Herr, R. J. Bioorg. Med. Chem. 2002, 10, 3379-3393. doi:10.1016/S0968-0896(02)00239-0

12. Burger, A. Isosterism and bioisosterism in drug design. In Progress in Drug Research; Jucker, E., Ed.; Birkhäuser: Basel, Switzerland, 1991; Vol. 12, pp 287-371. doi:10.1007/978-3-0348-7139-6_7 
13. Butler, R. N.; Katritzky, A. R.; Rees, C. W.; Scriven, E. F. V., Eds Comprehensive Heterocyclic Chemistry; Pergamon Press: Oxford, United Kingdom, 1996.

14. Habibi, D.; Nasrollahzadeh, M.; Mehrabi, L.; Mostafaee, S. Monatsh. Chem. 2013, 144, 725-728. doi:10.1007/s00706-012-0871-9

15. Nasrollahzadeh, M.; Jaleh, B.; Jabbari, A. RSC Adv. 2014, 4, 36713-36720. doi:10.1039/C4RA05833J

16. Shahroosvand, H.; Najafi, L.; Mohajerani, E.; Janghouri, A.; Nasrollahzadeh, M. RSC Adv. 2013, 3, 6323-6326. doi:10.1039/c3ra40267c

17. Nasrollahzadeh, M.; Sajadi, S. M.; Rostami-Vartooni, A.; Khalaj, M. RSC Adv. 2014, 4, 43477-43484. doi:10.1039/C4RA07173E

18. Nasrollahzadeh, M.; Sajadi, S. M.; Rostami-Vartooni, A.; Bagherzadeh, M. J. Colloid Interface Sci. 2015, 448, 106-113. doi:10.1016/j.jcis.2015.02.009

19. Porte, A.; Godoy, R. L. O. J. Serb. Chem. Soc. 2008, 73, 307-310. doi:10.2298/JSC0803307P

20. Nasrollahzadeh, M.; Sajadi, S. M.; Rostami-Vartooni, A.; Bagherzadeh, M.; Safari, R. J. Mol. Catal. A: Chem. 2015, 400, 22-30. doi:10.1016/j.molcata.2015.01.032

21. Nasrollahzadeh, M.; Sajadi, S. M.; Rostami-Vartooni, A.; Khalaj, M. J. Mol. Catal. A: Chem. 2015, 396, 31-39. doi:10.1016/j.molcata.2014.09.029

22. Aghabarari, B.; Dorostkar, N. J. Taiwan Inst. Chem. Eng. 2014, 45, 1468-1473. doi:10.1016/j.jtice.2014.03.006

23. Sternik, D.; Majdan, M.; Deryło-Marczewska, A.; Żukociński, G.; Gładysz-Płaska, A.; Gun'ko, V. M.; Mikhalovsky, S. V. J. Therm. Anal. Calorim. 2011, 103, 607-615. doi:10.1007/s10973-010-1014-3

24. Zhironga, L.; Uddinb, M. A.; Zhanxue, S. Spectrochim. Acta, Part A: Mol. Biomol. Spectrosc. 2011, 79 1013-1016. doi:10.1016/j.saa.2011.04.013

25. Caglar, B.; Afsin, B.; Tabak, A.; Eren, E. Chem. Eng. J. 2009, 149, 242-248. doi:10.1016/j.cej.2008.10.028

26. Mozgawa, W. J. Mol. Struct. 2000, 555, 299-304. doi:10.1016/S0022-2860(00)00613-X

27. Leite, I. F.; Soares, A. P. S.; Carvalho, L. H.; Raposo, C. M. O.; Malta, O. M. L.; Silva, S. M. L. J. Therm. Anal. Calorim. 2010, 100, 563-569. doi:10.1007/s10973-009-0265-3

28. Ayodele, O. B.; Togunwa, O. S. Appl. Catal., A 2014, 470, 285-293. doi:10.1016/j.apcata.2013.11.013

29. Dang, T. M. D.; Le, T. T. T.; Fribourg-Blanc, E.; Dang, M. C. Adv. Nat. Sci.: Nanosci. Nanotechnol. 2011, 2, 025004. doi:10.1088/2043-6262/2/2/025004

30. Nasrollahzadeh, M.; Sajadi, S. M.; Hatamifard, A. J. Colloid Interface Sci. 2015, 460, 146-153. doi:10.1016/j.jcis.2015.08.040

31. Nasrollahzadeh, M.; Sajadi, S. M.; Rostami-Vartooni, A.; Khalaj, M. J. Colloid Interface Sci. 2015, 453, 237-243. doi:10.1016/j.jcis.2015.04.047

32. Nasrollahzadeh, M.; Sajadi, S. M. J. Colloid Interface Sci. 2015, 457, 141-147. doi:10.1016/j.jcis.2015.07.004

33. Nasrollahzadeh, M.; Sajadi, S. M.; Khalaj, M. RSC Adv. 2014, 4, 47313-47318. doi:10.1039/C4RA08863H

34. Salem, S.; Salem, A.; Babaei, A. A. J. Ind. Eng. Chem. 2015, 23 , 154-162. doi:10.1016/j.jiec.2014.08.009

35. Su, W.-K.; Hong, Z.; Shan, W.-G.; Zhang, X.-X. Eur. J. Org. Chem. 2006, 2006, 2723-2726. doi:10.1002/ejoc.200600007
36. Li, S.; Guo, S.; Yang, H.; Gou, G.; Ren, R.; Li, J.; Dong, Z.; Jin, J.; Ma, J. J. Hazard. Mater. 2014, 270, 11-17. doi:10.1016/j.jhazmat.2014.01.033

37. Hayakawa, K.; Yoshimura, T.; Esumi, K. Langmuir 2003, 19 , 5517-5521. doi:10.1021/la034339l

38. Veerakumar, P.; Velayudham, M.; Lu, K.-L.; Rajagopal, S. Appl. Catal., A 2012, 439-440, 197-205. doi:10.1016/j.apcata.2012.07.008

39. Choi, Y.; Bae, H. S.; Seo, E.; Jang, S.; Park, K. H.; Kim, B.-S. J. Mater. Chem. 2011, 21, 15431-15436. doi:10.1039/c1jm12477c

40. Liu, B.; Yu, S.; Wang, Q.; Hu, W.; Jing, P.; Liu, Y.; Jia, W.; Liu, Y.; Liu, L.; Zhang, J. Chem. Commun. 2013, 49, 3757-3759. doi:10.1039/c3cc40665b

41. Lee, J.; Park, J. C.; Song, H. Adv. Mater. 2008, 20, 1523-1528. doi:10.1002/adma.200702338

42. Wang, Z.; Xu, C.; Gao, G.; Li, X. RSC Adv. 2014, 4, 13644-13651. doi:10.1039/c3ra47721e

\section{License and Terms}

This is an Open Access article under the terms of the Creative Commons Attribution License (http://creativecommons.org/licenses/by/2.0), which permits unrestricted use, distribution, and reproduction in any medium, provided the original work is properly cited.

The license is subject to the Beilstein Journal of

Nanotechnology terms and conditions:

(http://www.beilstein-journals.org/bjnano)

The definitive version of this article is the electronic one which can be found at: doi:10.3762/bjnano.6.236 